$12.1 ; 13.2$

\title{
Особенности полевой десорбции натрия и цезия с поверхности науглероженного рениевого полевого эмиттера
}

\author{
(ㄱ Д.П. Бернацкий, В.Г. Павлов \\ Физико-технический институт им. А.Ф. Иофрфе РАН, Санкт-Петербург, Россия \\ E-mail: bernatskii@ms.ioffe.ru
}

Поступило в Редакцию 27 марта 2020 г.

В окончательной редакции 27 марта 2020 г.

Принято к публикации 3 апреля 2020г.

\begin{abstract}
Методом полевой эмиссионной микроскопии исследована полевая десорбция атомов натрия и цезия с рениевого полевого эмиттера, предварительно науглероженного в парах бензола. Обнаружено различие в зависимостях ионного тока $\mathrm{Na}$ и Cs от приложенного к полевому эмиттеру напряжения. Различие в зависимостях ионного тока объясняется образованием многослойного графена на кристаллической поверхности рениевого полевого эмиттера в областях низкоиндексных граней и его интеркалированием атомами щелочных металлов с разными потенциалами ионизации и разными атомными и ионными радиусами.
\end{abstract}

Ключевые слова: полевая десорбция, натрий, цезий, науглероженный рений, многослойные графеновые наноструктуры, полевые эмиттеры.

DOI: 10.21883/PJTF.2020.13.49589.18321

Получение графитовых структур на поверхности металлических полевых эмиттеров, влияющих на эмиссионные, эксплуатационные и конструкционные свойства, открывает новые возможности для улучшения параметров эмиттеров и является важной научной и практической задачей [1-3]. В работах $[4,5]$ была показана возможность получения графена на плоских образцах многих металлов, в частности рения, при диссоциации молекул бензола на поверхности. В настоящей работе с помощью полевой эмиссионной микроскопии [6] проведено исследование влияния образования многослойного графена на квазисферической поверхности рениевого полевого эмиттера на полевую десорбцию натрия и цезия, адсорбированных на поверхности эмиттера. Атомы натрия и цезия интеркалируют графитовые структуры при комнатных температурах и имеют малые потенциалы ионизации. Это облегчает получение десорбционных изображений поверхности для визуализации образования графитовых наноструктур. Визуализация распределения слабых электронных и ионных токов осуществляется с помощью двух микроканальных пластин и люминесцентного экрана.

Образец для исследований в виде острия с радиусом вершины порядка $500 \mathrm{~nm}$ изготавливался из рениевой проволоки путем электрохимического травления. В высоковакуумной камере полевого эмиссионного микроскопа осуществлялся отжиг эмиттера при температуре $T=2500 \mathrm{~K}$, во время которого происходили очистка и формирование поверхности монокристаллической вершины острия. После формирования образца появляется стандартное полевое электронное изображение [7] квазисферической поверхности кристалла рения с центральной гранью (11히). Науглероживание образца проводилось в парах бензола при давлении в камере $\sim 10^{-5}$ Torr при температуре образца $1800 \mathrm{~K}$ в течение $40 \mathrm{~min}$. При указанных параметрах происходит диссоциация бензола на поверхности рения и растворение углерода в его объеме. При охлаждении образца углерод может выходить на поверхность с образованием многослойного графенового покрытия и понижением работы выхода [8].

После науглероживания наблюдалось снижение работы выхода поверхности полевого эмиттера от значения $4.9 \mathrm{eV}$ (чистый рений) до значения $4.3 \mathrm{eV}$, что характерно для образования графенового покрытия [5]. При этом напряжение появления полевого электронного изображения понижалось с 10 до $7.8 \mathrm{kV}$. Изменение работы выхода вычислялось из характеристик Фаулера-Нордгейма для полевой электронной эмиссии, измеренных до и после науглероживания образца. Полевое электронное изображение поверхности эмиттера после науглероживания изменилось: появилась электронная эмиссия с областей, где расположены четыре грани рения типа (0111).

Напыление атомов натрия на поверхность науглероженного рения приводило к снижению работы выхода поверхности и уменьшению напряжения появления полевого электронного изображения $\left(U_{E}\right)$ поверхности. С увеличением степени покрытия работа выхода уменьшалась до минимального значения $(\varphi=2 \mathrm{eV})$. При напылении атомов цезия, имеющих меньший потенциал ионизации, наблюдались аналогичные зависимости от степени покрытия, а минимальное значение работы выхода составило $\varphi=1.4 \mathrm{eV}$.

B режиме полевой десорбции (положительное напряжение на эмиттере) были получены полевые десорбционные изображения поверхности эмиттера при напылении атомов натрия. Напряжение появления полевого электронного изображения составило $4.3 \mathrm{kV}$, а вычис- 

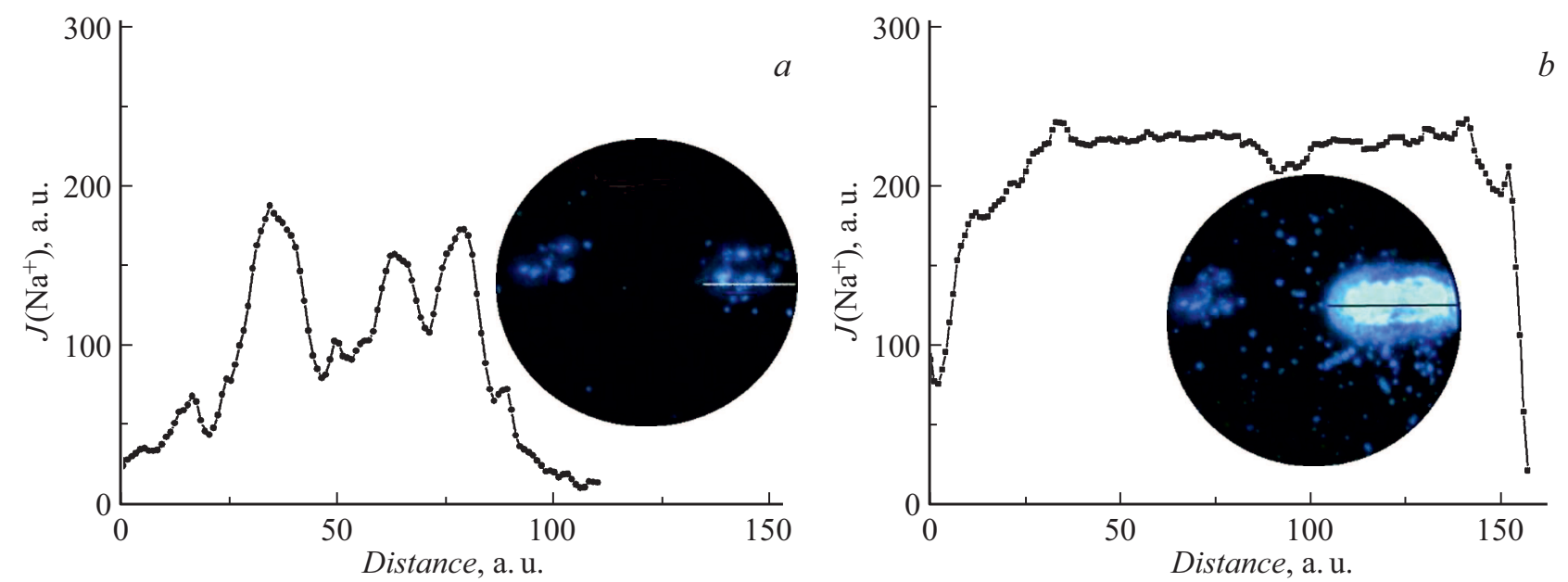

Рис. 1. Распределение тока полевой десорбции натрия с грани типа (0111) науглероженного рения. $a-$ начальная стадия, $b-$ конечная стадия (вспышка). На вставках приведены полевые десорбционные изображения эмиттера.
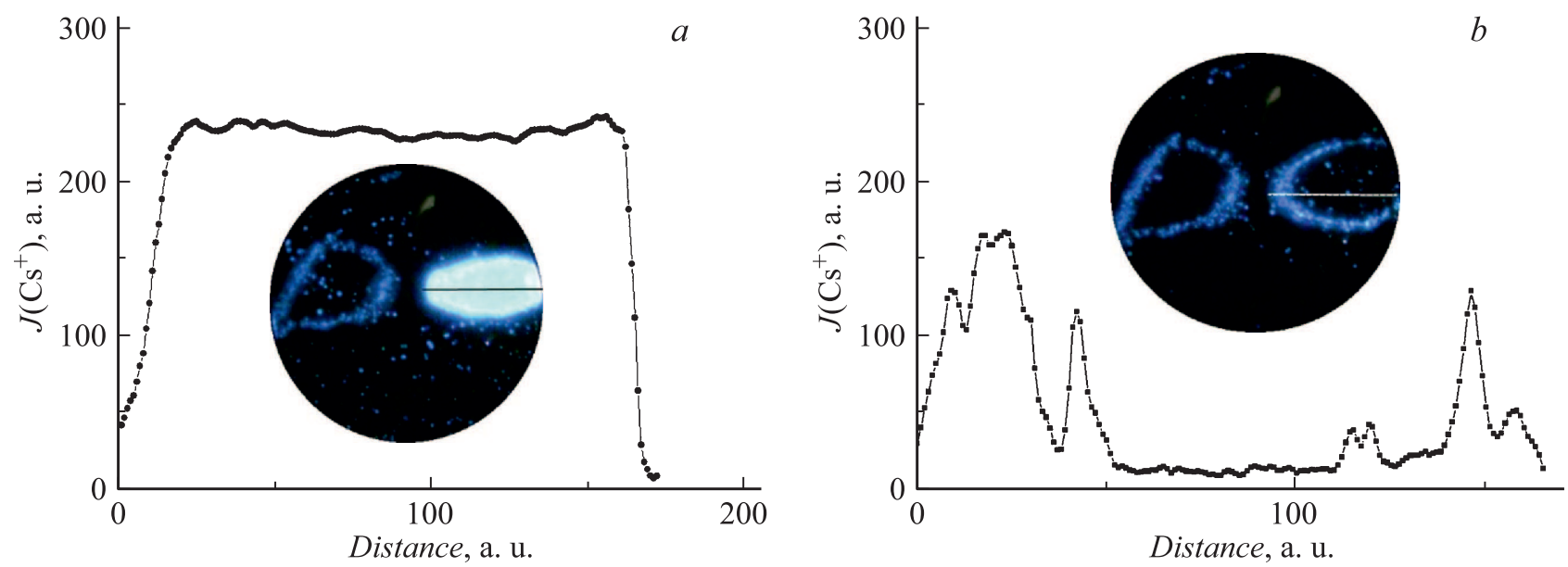

Рис. 2. Распределение тока полевой десорбции цезия с грани типа (011̄1) науглероженного рения. $a-$ начальная стадия (вспышка), $b$ - конечная стадия. На вставках приведены полевые десорбционные изображения эмиттера.

ленное из характеристик Фаулера-Нордгейма значение работы выхода равнялось $2.8 \mathrm{eV}$. Это область покрытий, близких к оптимальному покрытию. По сравнению с полевой десорбцией щелочных металлов с чистых металлов, где присутствует одна фаза десорбции в виде вспышки ионов со всей поверхности эмиттера [6], полевая десорбция атомов натрия с науглероженного рения имеет существенные отличия. При увеличении напряжения на эмиттере до $U_{D}=20 \mathrm{kV}$ начинается десорбция атомов натрия с граней типа (01시). На рис. $1, a$ (вставка) показан экран десорбционного микроскопа, где видны две грани, попавшие на экран. Десорбция носит непрерывный характер и сохраняется при увеличении напряжения на эмиттере. Распределение тока ионов натрия по правой грани в горизонтальном сечении по центру грани, полученное из полевых десорбционных изображений с помощью программы ImageJ, приведено на рис. $1, a$. Из полученной зависимости видно, что ток ионов натрия крайне неоднороден по поверхности как по величине, так и по локализации. Отсутствие лавинообразной вспышки, характерной для чисто металлической поверхности, свидетельствует о возобновлении концентрации атомов натрия в зоне десорбции. Принимая во внимание эффекты интеркалирования щелочными металлами графитовых образований на рении [5], можно предположить, что механизмом возобновления концентрации атомов натрия на поверхности эмиттера является объемная диффузия атомов натрия из графита. При увеличении напряжения на эмиттере до $29 \mathrm{kV}$ наблюдается лавинообразная десорбция (вспышка) атомов натрия с правой грани (вставка на рис. $1, b$ ), а затем и с левой грани. Зависимость тока ионов натрия от напряжения приобретает импульсный характер, а распределение тока ионов натрия по области десорбции становится более равномерным (рис. $1, b)$. Появление вспышки десорбции указывает на уменьшение энергии активации десорб- 


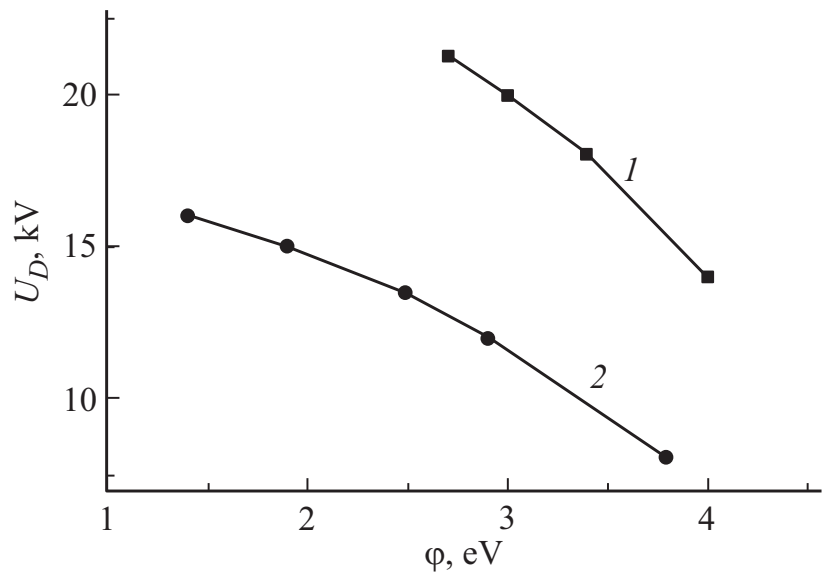

Рис. 3. Зависимость десорбирующего напряжения с науглероженного рения от работы выхода поверхности эмиттера. 1 для атомов натрия, 2 - для атомов цезия.

ции иона вследствие уменьшения концентрации атомов натрия на поверхности. Энергия активации десорбции однократно заряженного иона в модели сил изображения [9] определяется выражением $Q=Q_{0}-e^{3 / 2} F^{1 / 2}$, где $Q_{0}$ - энергия десорбции иона в отсутствие электрического поля, $e-$ заряд электрона, $F-$ напряженность приложенного электрического поля. Энергия десорбции иона $Q_{0}$ связана с энергией десорбции нейтрального атома $\Lambda$ выражением $Q_{0}=\Lambda(\theta)+I-\varphi(\theta)$, где $I-$ потенциал ионизации атома, $\varphi$ - работа выхода поверхности. Для щелочных металлов с ростом покрытия работа выхода поверхности уменьшается быстрее, чем энергия десорбции нейтрального атома $\Lambda$ [10]. Если поток десорбции превосходит приток атомов за счет диффузии, то покрытие и энергия десорбции иона $Q_{0}$ будут уменьшаться во время десорбции. Скорость десорбции растет и весь адсорбат десорбируется лавинообразно.

Можно предположить, что характер полевой десорбции атомов щелочных металлов при влиянии интеркаляции будет различаться для атомов разного атомного радиуса. Следовательно, если на том же образце вместо атомов натрия (атомный радиус $0.192 \mathrm{~nm}$, ионный радиус $0.098 \mathrm{~nm}$ ) адсорбировать атомы цезия с бо́льшими значениями атомных и ионных радиусов (атомный радиус $0.274 \mathrm{~nm}$, ионный радиус $0.165 \mathrm{~nm}$ ), следует ожидать изменения в характере полевой десорбции. После нанесения атомов цезия напряжение появления электронного изображения уменьшилось до значения $2.6 \mathrm{kV}$, что соответствовало работе выхода $2 \mathrm{eV}$ (степень покрытия цезием, близкая к оптимальному покрытию). На начальной стадии десорбции при увеличении напряжения на эмиттере $U_{D}$ до $14.3 \mathrm{kV}$ была зарегистрирована вспышка ионного тока (лавинообразная десорбция) с левой грани, а затем при напряжении $15 \mathrm{kV}$ появилась вспышка с правой грани (вставка на рис. 2,a). Распределение ионного тока цезия с области десорбции правой грани (полученное аналогично распределению для натрия, см. выше) приведено на рис. 2, $a$. Зависимость тока имеет форму импульса как во временно́м, так и в пространственном распределении. После вспышек с граней полевая десорбция цезия не пропала. Распределение ионного тока цезия и изображение полевой десорбции приведены на рис. 2, $b$. Характер полевой десорбции цезия с поверхности эмиттера изменился. Если на начальной стадии десорбции вспышка составляла сотые доли секунды, то после вспышки наступал непрерывный режим десорбции при увеличении напряжения до $20 \mathrm{kV}$. Такое поведение полевой десорбции можно объяснить малым потоком атомов цезия на поверхность из многослойного графена при объемной диффузии вследствие большего атомного радиуса цезия по сравнению с атомным радиусом натрия. Оставшийся контур десорбции в области граней (вставка на рис. 2, $b$ ), который сохраняется при увеличении напряжения, возможно, связан с большим значением напряженности электрического поля на границе многослойного графена и притоком атомов цезия по поверхности из областей, не занятых графитом.

На рис. 3 представлены зависимости десорбирующего напряжения $U_{D}$ от работы выхода поверхности. Как видно из рисунка, для атомов натрия (кривая 1 на рис. 3) и цезия (кривая 2 на рис. 3) десорбирующее напряжение $U_{D}$ уменьшается с ростом работы выхода $\varphi$, что согласуется с принятой моделью сил изображения для полевой десорбции. Кривая 1 для натрия (потенциал ионизации $I=5.14 \mathrm{eV}$ ) проходит выше кривой 2 для цезия (потенциал ионизации $I=3.89 \mathrm{eV}$ ), т.е. имеет бо́льшие значения десорбирующего напряжения, что также находится в согласии с моделью сил изображения для полевой десорбции.

Таким образом, обнаружены отличия полевой десорбции натрия и цезия с науглероженного рения от десорбции с чистого металла и особенности кинетики десорбции разных щелочных металлов. Обнаруженные особенности объясняются интеркалированием атомов щелочного металла многослойным графеном. Кинетика десорбции согласуется с моделью сил изображения для полевой десорбции.

\section{Финансирование работы}

Работа выполнена в рамках государственного задания по теме 0040-2014-0021.

\section{Конфликт интересов}

Авторы заявляют, что у них нет конфликта интересов.

\section{Список литературы}

[1] Nanofabrication using focused ion and electron. Principles and applications / Eds I. Utke, S. Moshkalev, P. Russell. Oxford University Press, 2012. $380 \mathrm{p}$.

[2] Kumar S., Duesberg G.S., Pratap R., Raghavan S. // Appl. Phys. Lett. 2014. V. 105. P. 103-107. 
[3] Шешин Е.П. Структура поверхности и автоэмиссионные свойства углеродных материалов. М: Изд-во МФТИ, 2001. $288 \mathrm{c}$.

[4] Rut'kov E.V., Gall N.R. // Physics and applications of graphene - experiments / Ed. S. Mikhailov. InTech, 2011. P. 209-292.

[5] Галль Н.Р., Рутьков Е.В. // Физика поверхности твердых тел. Графен и графит на поверхности твердых тел. СПб.: Изд-во Политехн. ун-та, 2013. С. 160.

[6] Берначкий Д.П., Павлов В.Г. // Изв. РАН. Сер. физ. 2009. T. 73. № 5. C. 713-715.

[7] Beach Th., Vanselow R. // Appl. Phys. 1974. V. 4. P. 265-270.

[8] Рутьков Е.В., АФанасьева Е.Ю., Лавровскал Н.П., Галль Н.P. // ФТТ. 2018. Т. 60. В. 5. С. 1024-1028.

[9] Muller E.W., Tsong T.T. // Field ion microscopy, field ionization and field evaporation. Pergamon Press, 1973. P. 81.

[10] Бернацкий Д.П., Павлов В.Г. // Письма в ЖТФ. 2018. Т. 44. B. 4. C. $103-109$ 